\title{
Mental health in women experiencing preterm birth
}

Aud R Misund ${ }^{1,3^{*}}$, Per Nerdrum ${ }^{1}$ and Trond H Diseth ${ }^{2,3}$

\begin{abstract}
Background: The aim of the study was to explore the degree of psychological distress, anxiety, and trauma related stress reactions in mothers who experience preterm birth. Secondarily, we wanted to identify possible predictors of maternal mental health problems.

Methods: Twenty-nine mothers of 35 premature children born before 33rd week of pregnancy were assessed within two weeks after given birth. The standardized psychometric methods; Impact of Event Scale (IES), General Health Questionnaire (GHQ) and State Anxiety Inventory (STAl) assessed mental health problems. The predictors for maternal distress, anxiety, and trauma related stress reactions were pregnancy variables, preterm delivery, Gestation Age, maternal trait anxiety and parity. In addition, maternal prevalence of mental health problems was assessed by clinical diagnoses.
\end{abstract}

Results: Our study revealed a high prevalence (52\%) of posttraumatic stress responses in the mothers.

Conclusions: Our results suggest an early examination of mothers' psychological reactions to preterm birth at the maternity ward. An early intervention should be considered while the child still is in the neonatal intensive care unit.

Keywords: Anxiety, Depression, Preterm birth, Psychological distress, PTSR

\section{Background}

In general, childbirth may become a traumatic event when intense fear, helplessness, pain and loss of control are experienced in labor and delivery $[1,2]$. Many of these factors are likely to be present in a preterm birth situation. For mothers, the experience of giving preterm birth, and the subsequent experiences in the neonatal intensive care unit (NICU), may therefore cause substantial psychological distress. Exploring maternal mental health reactions following preterm birth is interesting from an attachment perspective as maternal mental health is known to affect children's physical and mental development [3,4]. Previous research has shown that women with preterm deliveries experience significantly higher levels of stress and depression than women who deliver at term [5-10]. However, less is known of maternal posttrauma reactions to preterm birth [11]. Stress is a psychological phenomenon that may

\footnotetext{
* Correspondence: aud.misund@hioa.no

${ }^{1}$ Faculty of Health Sciences, University College of Oslo and Akershus, PO Box. 4 St. Olavs plass, N-0130 Oslo, Norway

${ }^{3}$ Department of Medicine, Institute of Clinical Medicine, University of Oslo, PO Box 1171 Blindern, 0318 Oslo, Norway

Full list of author information is available at the end of the article
}

present as anxiety, depression and trauma reactions. The co-morbidity of anxiety and depression in posttraumatic reactions is well known, but the knowledge of traumarelated stress reactions after preterm childbirth is still limited [12].

Behavioral and cognitive problems in prematurely born infants have been the main focus in research for several decades [13]. In addition to the severity of the child's medical risk factors, parental mental health is known to contribute substantially to children's cognitive, emotional, social and physical development [13-16]. A number of studies have explored maternal depression following preterm birth. This research has reported that preterm mothers are at higher risk of depression than term mothers shortly after preterm birth and that mothers with very-lowbirth-weight infants have a continued risk for depression in the first postpartum year [10]. Furthermore, follow-up studies of term babies have shown that persisting parental depressive symptoms are an important predictor of child dysfunction $[17,18]$. The predictors of postpartum depression that have achieved the greatest amount of consensus are previous psychiatric disorder, higher family disposal of 
psychiatric disorder, as well as poor social support, marital problems, and a higher amount of stress during pregnancy [1].

We know that about 1.5 to $3 \%$ of full term birth women show signs of posttraumatic stress disorder (PTSD) 6 months after giving birth, however, the maternal trauma reactions following a preterm birth is less explored. But the trauma and post trauma connection, however, is still unexplained [19].

One study revealed that a preterm birth experience may cause a long lasting traumatizing effect on parents; $49 \%$ of the mothers reported significant trauma reactions one year after delivery [20]. Muller-Nix et al. found a correlation between traumatic stress reactions and disturbances in mother-child interaction [21]. The strength of parents' post-traumatic stress symptoms (PTSR) after preterm delivery is reported to be the most important predictor of the child's sleeping and eating problems [22]. However, studies of mental health problems after preterm delivery are in general small non-randomized studies with differing trauma measurements.

The primary aim of the present study was to explore the degree of psychological distress, anxiety, and traumarelated stress reactions in mothers who deliver preterm. Secondarily, we wanted to explore the nature of maternal psychological distress and identify the predictors of maternal mental health problems.

\section{Methods}

\section{Study design}

This study used an explorative cohort design.

From June 2005 to July 2008 through two periods of 8 and 10 months, the psychological responses of 29 consecutive mothers of 35 premature children born before 33rd week of pregnancy at the Oslo University Hospital, Norway were assessed. The data collection was performed as soon as the mothers were able to attend the interview after preterm childbirth, (median 11 days (4-30)). Mothers of severely ill babies with uncertain survival and nonNorwegian speakers were not included. Medical charts and questionnaires were used to collect data about the childbirth, the child's physical state, maternal previous mental health history, and socio-demographics.

The study group was a homogeneous group with high scores on socio-demographic variables like education, income, and housing standard. They all lived in a relatively affluent city district in the Oslo area. Most of them were giving birth first time late in their twenties or early thirties. All of them lived with the child's father and none reported any relationship problems. Only two mothers were diagnosed with a chronic somatic illness. Twenty-eight percent of the mothers had become pregnant by IVF.
The babies in the study group had relatively high Apgar mean scores and only $23 \%$ of the babies needed mechanical ventilation for more than 24 hours.

The neonatal intensive care unit had applied several aspects of the newborn individualized developmental care and assessment program (NIDCAP) in their care for the preterm babies and in their parental support and supervising [23]. The parents included in the study were offered psychological care during hospital stay. Mothers with high levels of mental health reactions were referred to further psychological treatment after hospitalization.

\section{Measurements of maternal mental health problems}

Maternal mental health problems were measured by the standardized psychometric methods Impact of Event Scale (IES), General Health Questionnaire (GHQ), and State/ Trait Anxiety Inventory (STAI-X1/X2).

The 15-item version of the Impact of Event Scale (IES) [24] was used to assess behavioral aspects of distress. Clinically important stress related cognition and behavior were defined as an IES score $\geq 19$. In this study, the stress factor was defined as "Preterm childbirth". The IES-15 has two subscales measuring symptoms of intrusive psychological distress (7 items) and avoidant cognition and behavior (8 items). Intrusion is characterized by unbidden thoughts and images, troubled dreams, strong pangs or waves of feelings, and repetitive behavior. Avoidance responses include ideational constriction, denial of the meaning and consequences of the event, blunted sensation, behavioral inhibition or counter-phobic activity, and awareness of emotional numbness. The scoring range for each item is 0 (not at all) to 5 (very much). A subscale score of 0-8 usually denotes minor responses, 9-19 moderate responses and scores $\geq 20$ denote severe responses. IES has been thoroughly validated and is one of the key psychometric assessments methods in traumatic stress research [24,25].

The General Health Questionnaire (GHQ) [26] is a widely used screening instrument for assessing the presence of distress, psychopathology, and overall well-being, showing well established reliability and validity. The GHQ includes both positive and negative questions, and the short version GHQ-30 contains 30 items covering symptoms considered to reflect psychological distress and the subscales for depression and feelings of incompetence/low self-esteem (also referred to as well-being). Each question is answered on a four point scale. The answers to each item may be treated both as Likert sum score (recommended for use in longitudinal studies when measuring change) with weights assigned to each response (0-1-2-3) with a possible scale of $0-90$, and as case sum score with weights (0-0-1-1) and possible range $0-30$. When using the GHQ-30 as a screening instrument for overall psychological distress, as in this study, case-score has exhibited acceptable values for sensitivity and specificity. Clinically 
important psychological distress was defined as case total scores $\geq 6$ [26-28].

The Spielberger State Trait Anxiety Inventory (STAI-X1 and STAI-X2) [29] was used to assess maternal anxiety. STAI-X1 is a measure of state anxiety levels reflecting subjective feelings of tension, apprehension, nervousness and worry. STAI-X1 has a 20 item and a 12 item version. The 12 item STAI-X1 was used in the first data collection period and the 20 item STAI-X1was used in the second data collection period. Both versions consist of items eliciting to what extent the respondent is currently experiencing the symptom or sign: "Not at all", "Somewhat", "Moderately" or "Very much" and rated on a four-step scale (1-2-3-4) with a possible score range of $20-80$ for the 20 item version and $12-48$ for the 12 item version. Higher scores indicate more anxiety.

Ten items from the 20 items version are overlapping in the two versions (item no: $1,2,3,5,7,11,12,13,14$, 15). A common 10 item STAI version was constructed for our analyses. For the 10 item version clinically important state anxiety was defined as a STAI score $\geq 20$ (corresponding to $\geq 40$ for 20 item version). STAI-X2 is a measure of trait anxiety that refers to individual differences in anxiety proneness i.e. in the tendency to see the world as dangerous and threatening, and in the frequency with which anxiety states are experienced. It consists of 20 items and the scoring range is $20-60$. Clinically important significant trait anxiety was defined as $\geq 40$.

STAI-X1 and X2 are reliable and widely used selfevaluation questionnaires that have been used in several studies in similar populations [29].

To explore the prevalence of anxiety, depression, and PTSR in particular, a tentative clinical diagnosis or not, based on the clinical diagnostic guidelines in the ICD-10 Classification of mental and behavioural disorders [30], was assessed by a psychiatrist (last author). The assessment was based on all information available in a clinical perusal of the psychometric self-reports IES, GHQ and STAI of each of the 29 preterm mothers, and blinded to the physical and socio-demographic characteristics of the mothers and their children.

\section{Statistical methods}

Values of continuous variables are presented as means (SD) or if skewed as median and range. Categorical variables are given as proportions and percentages. Correlations between normally distributed and continuous variables were measured using Pearson's correlation coefficient or Spearman's correlation coefficient when the variables had a skewed distribution. Forward linear regression analysis was used to identify possible predictors of mental health and psychological distress within the study group. The three variables with the strongest bivariate associations were included in the multiple linear regression model. A careful check of the model assumptions, including an investigation of residual plots, did not reveal any violation of the assumptions. All analyses were performed in SPSS version 18. Two-sided statistical tests were applied, a $5 \%$ statistical significance level was chosen.

\section{Ethics}

Written informed consent was obtained from participants prior to study start. The study protocol was approved by the Norwegian National Committee for Research Ethics (S-05068 and S-07096b) and by the Data Inspectorate (12360 and 07/1088). The study protocol was carried out in accordance with the Declaration of Helsinki.

\section{Results}

Twenty-nine of 34 families (85.3\%) that met the inclusion criteria were included in the study group. Five mothers refused to participate in the study. The reasons for refusal were lack of energy or mental capacity or lack of time for being interviewed. None of the families that refused to participate differed from the participants regarding characteristics of the child's medical condition or socio-demographic background.

Baseline physical and socio-demographic characteristics of mothers and children are shown in Table 1.

\section{Maternal mental health problems}

The mothers in the study group reported significant mean scores in the clinical important range for psychological distress in all items on IES, GHQ and STAI (Table 2). Regarding the IES subscales, the Intrusion subscale showed the highest mean score. The proportion of Intrusion case score were $65.5 \%$, while the proportion of Avoidance case score was $27.6 \%$ (Table 3 ).

The clinical diagnosis assessment revealed that $28 \%$ of the mothers had depression, $17 \%$ had anxiety and 52\% PTSR. Twenty-one percent of the mothers had more than one diagnosis.

\section{Associations between physical variables and maternal mental health problems}

There were significant bivariate associations between several physical variables (planned Cesarean section, GA, birth weight, Apgar score, need of mechanical ventilation, patent ductus arteriosis (PDA), neonatal surgery), mother's education, trait anxiety, parity, and previous psychological problems (Table 4). Increased maternal mental health problems were significantly associated with the mother's education, trait anxiety, parity and the child's GA, birth weight, and Apgar score. Other physical problems in pregnancy like planned Caesarean section and physical neonatal complications (mechanical ventilation, neonatal surgery, patent ductus arteriosis) were inversely associated with maternal mental health problems. 
Table 1 Socio-demographic and physical characteristics of the mothers given preterm birth and their children

\begin{tabular}{|c|c|}
\hline Mothers & $n=29$ \\
\hline Age; mean (SD) & $33.7(4.3)$ \\
\hline Education > 12 years; $n$ (\%) & $26(89.7)$ \\
\hline Single parent; n (\%) & $0(0)$ \\
\hline Unemployed; n (\%) & $4(13.8)$ \\
\hline Previous psychological treatment; $n(\%)^{a}$ & $8(27.6)$ \\
\hline Chronic illness; n (\%) & $2(6.9)$ \\
\hline Tot. no. of children; mean (SD) & $1.7(0.8)$ \\
\hline Previous pregnancies; mean (SD) & $1.1(1.5)$ \\
\hline Previous childbirths; mean (SD) & $0.5(0.7)$ \\
\hline First time mothers; n (\%) & $18(62.1)$ \\
\hline IVF pregnancy; n (\%) ${ }^{c}$ & $8(27.6)$ \\
\hline Bleeding in pregnancy; n (\%) & $19(65.5)$ \\
\hline Preeclampsia; n (\%) & $4(14.3)$ \\
\hline Pregnancy infection; n (\%) & $12(41.4)$ \\
\hline Cesarean emergency; n (\%) & $14(48.3)$ \\
\hline Cesarean planned; n (\%) & $3(10.3)$ \\
\hline Vaginal birth; n (\%) & $12(41.4)$ \\
\hline Breech birth; n (\%) & $3(8.6)$ \\
\hline Children & $\mathrm{n}=35$ \\
\hline Girl; n (\%) & $17(48.6)$ \\
\hline Boy; n (\%) & $18(51.4)$ \\
\hline Twin; n (\%) & $14(40.0)$ \\
\hline \multicolumn{2}{|l|}{ Gestational age (weeks); } \\
\hline Median (range) & $29(24-32)$ \\
\hline Mean (SD) & $28.5(2.6)$ \\
\hline \multicolumn{2}{|l|}{ Birth weight $(\mathrm{kg})$; } \\
\hline Median (range) & $1.2(0.6-2.0)$ \\
\hline Mean (SD) & $1.2(0.4)$ \\
\hline Apgar score at 1 minute; median (SD) & $6.3(2.3)$ \\
\hline Apgar score at 5 minutes; median (SD) & $7.6(2.0)$ \\
\hline Apgar score at 10 minutes; median (SD) & $8.3(1.0)$ \\
\hline Mechanical ventilation > 24 hours; $n$ (\%) & $8(22.9)$ \\
\hline Oxygen supply > 28 days; $n$ (\%) & $19(54)$ \\
\hline IVH grade 1 and $2 ; n(\%)^{d}$ & $5(14.3)$ \\
\hline IVH grade 3 and $4 ; n(\%)^{d}$ & $2(5.7)$ \\
\hline Surgery & $4(11.4)$ \\
\hline Infection & $7(20.0)$ \\
\hline Patent ductus arteriosis & $6(17.1)$ \\
\hline
\end{tabular}

${ }^{a}$ Everyone who had been in psychotherapy as a child or as an adult was registered.

bDiabetes and Crohn's disease.

'In vitro fertilization/Assisted fertilization.

dintraventricular hemorrhage following birth.
Table 2 Psychological distress, anxiety and trauma related stress reaction in mothers given preterm birth

Mean (standard error)

$n=29$

Impact of event scale

Sum total score (0-75)

$19.66(2.00)$

Sum Intrusion score (0-35)

$14.00(1.48)$

Sum Avoidance score (0-40)

$5.66(0.81)$

General health questionnaire

Sum GHQ Likert score (0-90)

$40.10(2.90)$

Sum GHQ case score (0-30)

$12.76(1.40)$

State anxiety inventory*

Sum total score $(0-40)$

$21.45(0.53)$

*10 question version of STAI-X1.

At the $10 \%$ statistical significance level previous psychological treatment and intraventricular hemorrhage (IVF) grade 1 or 2 were associated with increased maternal mental health problems measured by the GHQ and the IES scale, respectively.

\section{Predictors of maternal mental health problems}

The results of the forward multiple regression analyses are shown in Table 5. There was one significant predictor of the IES. "Planned Caesarean section" explained $10 \%$ of the variance in the IES $(p<0.05)$. Planned Caesarean was negative $(\hat{b}=-14.46)$ meaning that planned Caesarean section predict low IES scores. "Maternal trait anxiety" measured by STAI-X2 and "Other infection in pregnancy than preeclampsia" were significant predictors of GHQ Likert sum scores and explained $30 \%$ of the variance $(p<0.01, p<$ $0.05)$. While "Maternal trait anxiety" predicted high GHQ Likert sum scores $(\hat{b}=1.97)$, infection in pregnancy predicted low GHQ scores $(\hat{b}=-2.60)$. The significant predictors of STAI-X1 were the "Child's Gestational Age (GA) at birth" and "Parity", explaining $41 \%$ of the variance ( $p<0.001$ and $p<0.01$, respectively).

Table 3 Proportion of clinically important psychological distress, anxiety and trauma related stress

$\mathrm{n}=\mathbf{2 9}$

Impact of event scale

Case total $\geq 19$

$44.8 \%$

Case intrusion, moderate (9-19) $\quad 31.0 \%$

Case intrusion, severe $\geq 20$

$34.5 \%$

Case avoidance, moderate (9-19)

General health questionnaire

Case total, $\geq 6$

State anxiety inventory*

Case total, $>20$

$59.0 \%$

*10 question version of STAI-X1. 
Table 4 Significant correlations between socio-demographic, physical, and maternal mental health outcome variables

\begin{tabular}{|c|c|c|c|}
\hline & IES & $\mathrm{GHQ}^{\mathrm{d}}$ & STAI-X1 \\
\hline \multicolumn{4}{|l|}{ Mother } \\
\hline Age & & & $0.32^{\prime}$ \\
\hline Education (years) & & & $0.51^{* *}$ \\
\hline Previous psychological treatment & & $0.30^{\prime}$ & \\
\hline Parity & & & $0.42^{*}$ \\
\hline Trait anxiety (STAI-X2) & $0.32^{\prime}$ & $0.49^{* *}$ & \\
\hline \multicolumn{4}{|l|}{ Pregnancy/birth } \\
\hline Infection in pregnancy & & $-0.34^{*}$ & $-0.30^{\prime}$ \\
\hline Planned Caesarean & $-0.36^{*}$ & & \\
\hline Breech birth & $0.31^{\prime}$ & & \\
\hline \multicolumn{4}{|l|}{ Child } \\
\hline Sex & & & $-0.30^{\prime}$ \\
\hline GA & & & $0.52^{* *}$ \\
\hline Birth weight & & & $0.39^{*}$ \\
\hline 10 min Apgar score & & & $0.38^{*}$ \\
\hline Mechanical ventilation & & & $-0.43^{* *}$ \\
\hline $\mathrm{IVH} \mathrm{H}^{\mathrm{a}}$ & $0.30^{\prime}$ & & \\
\hline Surgery ${ }^{b}$ & & & $-0.37^{*}$ \\
\hline Patent ductus arteriosis ${ }^{c}$ & & & $-0.42^{*}$ \\
\hline
\end{tabular}

Pearson's correlation coefficients $(\mathrm{p}<0.10)$ are reported. $(\mathrm{N}=35)$.

'Correlation is significant at the 0.10 level (two-tailed).

${ }^{*}$ Correlation is significant at the 0.05 level (two-tailed)

** Correlation is significant at the 0.01 level (two-tailed).

antraventricular haemorrhage grade 1 or 2 .

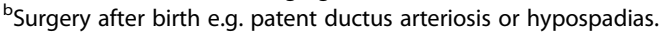

'Patent ductus arteriosis closed by medical treatment, surgery or by itself.

${ }^{\mathrm{d}}$ The GHQ in this table refers to Likert sum scores.

A further forward multiple regression analysis was performed of the IES subscales. The results yielded "Planned Caesarean section" as a predictor of low IES Intrusion sum scores $(p<0.05)$, and "Vaginal delivery" was found to be a predictor of high IES Avoidance sum scores $(p<0.05)$. The two predictors explained $8 \%\left(\mathrm{R}^{2}\right.$ adjusted $\left.=.08\right)$ and $10 \%$ ( $\mathrm{R}^{2}$ adjusted $\left.=.10\right)$, respectively, of the variance.

\section{Discussion}

The present study revealed that mothers who delivered preterm reported levels of psychological distress in the clinically important significant range two weeks after delivery.

In this study we detected that $52 \%$ of the mothers showed traumarelated symptoms and less than one third of the mothers showed symptoms of depression two weeks after the preterm delivery. The predictors for maternal mental health problems following preterm birth were related to the pregnancy, the preterm delivery, the child's GA, the maternal trait anxiety, and parity.

Epidemiologically high levels of mental health problems has been revealed [31,32]. The prevalence of mental health problems in Norway is reported to be in accordance with prevalence in other European countries; about 30\% in a 12 -month period and about $50 \%$ in a lifetime span [32-34]. The high prevalence of maternal stress and anxiety following preterm delivery in our study corresponds with previous studies [5-8]. Our results are considerably higher than expected when we compare them with other pure samples of patients with physical illness only [26]. Whether psychological distress should be seen as a normal reaction to preterm birth or not is still an open question. Compared with another Norwegian study of mothers giving birth at term for instance we found a prevalence of clinically important maternal psychological distress of $79 \%$, while they reported 37\% [35]. In addition, the same study detected that $9 \%$ of the term mothers reported severe intrusive stress symptoms in IES. In comparison $34.5 \%$ of the preterm mothers in our study reported severe intrusive stress symptoms in IES.

The clinical diagnostic assessment of the preterm mothers showed that posttraumatic stress reactions (PTSR) represented the most common reactions. The prevalence of PTSR, depression, and anxiety was $52 \%, 28 \%$, and $17 \%$, respectively. Our results are comparable to a study that reported $49 \%$ significant trauma reactions among mothers one year after delivery [20], but differ from another study which revealed a relation between high levels of maternal posttraumatic stress symptoms $(>33 \%)$ and high levels of depression $(>53 \%)$ [36]. Interestingly we revealed a high prevalence of severe intrusion stress symptoms measured by IES. Our result is comparable to another study that reported higher mean scores in the IES intrusion subscale in a preterm sample at discharge from the hospital [20]. Our study showed that preterm delivery may represent a

Table 5 Forward entry multiple regression analyses predicting mental health outcomes for mothers after preterm birth

\begin{tabular}{lllllll}
\hline Dependent variable & Independent variable & B & $\mathbf{9 5 \% ~ C l}$ & Beta & p-value & $\mathbf{R}_{\text {adj }}^{2}$ \\
\hline IES & Planned Caesarean section & -14.46 & $(-27.67,-1.25)$ & -0.36 & 0.033 & 0.10 \\
GHQ & Maternal trait anxiety & 1.97 & $(0.80,3.14)$ & 0.49 & 0.002 & 0.031 \\
& Infection in pregnancy & -5.14 & $(-9.79,-0.49)$ & -0.32 & 0.30 \\
STAI-X1 & GA (weeks in pregnancy) & 0.57 & $(0.28,0.86)$ & 0.52 & 0.000 \\
& Parity & 0.42 & $(0.63,2.79)$ & 0.42 & 0.003 \\
\hline
\end{tabular}

Unstandardized $(B)$ and standardized (Beta) regression coefficients. $(\mathrm{N}=35)$. 
significant trauma experience for the mother and that the prevalence of depression and anxiety was low compared to post-traumatic stress responses.

Planned Caesarean section was found to predict both low IES sum scores in the forward multiple regression analysis. In the study group, most of the Caesareans were emergency, but for a few hospitalized mothers with different physical issues like infections or growth retardation in fetus, the Caesarean section was planned some time in advance, and they had at least about a week to prepare themselves for the procedure. The results of the IES analyses may indicate that time to prepare oneself of a preterm birth as a planned Caesarean could reduce the traumatic stress response.

The child's gestational age (GA) at birth and maternal parity were the predictors of maternal stress and anxiety state levels (STAI-X1). It is noteworthy that numbers of previous childbirths are related to high anxiety state sum scores. The association between high GA and high levels of state stress and anxiety corresponds with findings in a study of term birth with ultrasound detections [37]. A Norwegian study on maternal psychological responses after ultrasound scan at 18 weeks of GA, with or without detection of fetal anomalies, also reported that advanced GA at diagnosis of fetal anomalies was one of the strongest predictors of psychological distress [38].

There may be several variables that could explain why advanced GA predict high levels of psychological distress. The preparation for the motherhood is close in time and first time mothers may worry about their limited experiences with parenthood. In addition, our results may be hypothesized to be a result of growing relationship to the fetus during pregnancy $[39,40]$. The "fear of losing the baby" evoked by a preterm birth and "growing relationship" to the baby are probably closely related. Several studies have focused on preterm deliveries and the "fear of losing the baby", and on the relationship between the "intensity of grief" and increasing GA, when mothers have experienced pregnancy termination or pregnancy loss [41-43].

A recent study including an attachment research instrument (Adult Attachment Projective) revealed that $67 \%$ of mothers that had experienced a preterm birth showed unresolved posttraumatic issues regarding the "anxiety of losing the baby" 6 years after the preterm birth $[42,44]$. In attachment theory, a "threat" is understood as a crucial element in the onset of human behavioral strategies [45] and psychological distress might be the result when the strategies do not work or do not eliminate the "threat". "fear of losing the baby" is likely to be experienced as a "threat" in a psychological sense. Attachment theory might well represent a theoretical framework that could broaden our understanding of the high levels of the maternal mental health responses after a preterm birth in our study.
Personal vulnerability factors such as previous mental health problems and trait anxiety were associated with general psychological distress in the GHQ Likert sum scores, as well as being significant predictors of general psychological distress measured by GHQ Likert sum scores. Our finding corresponds with another study that explored the prevalence of post-traumatic stress symptoms following childbirth [46]. Thus, the maternal previous mental health history seems to be important to include in the medical charts of mothers that deliver at preterm when assessing the mother's need of psychological support after birth.

Our study revealed an inverse association between pregnancy complications and psychological distress, anxiety and trauma related stress. Pregnancy complications do not measure the mother's "fear of losing the baby" explicitly, but may be an indicator of this phenomenon. Indeed the pregnancy complication variables "planned Caesarean section", and "infection in pregnancy" turned out to be the predictors of low maternal psychological distress and traumarelated stress scores in the IES and the GHQ. A planned Caesarean implies more control in labor than an emergency Caesarean or a spontaneous vaginal delivery. Previous studies that have explored the association between maternal distress and physical complications in pregnancy and in infants in the perinatal or postnatal period have reported results that run counter to those of our study [41,47-52].

Some of the results in our study have been difficult to explain but should be mentioned for future research purposes. For instance, we found an significant association in our correlation analysis between lower maternal mental health problems in STAI-X1 and two medical conditions the child was treated for after birth; the common condition patent ductus arteriosis (PDA) and the more severe hypospadias condition.

Medical conditions that require treatment and surgery may easily be assumed as distressing for the parents. Why these conditions lower the maternal anxiety in the STAI$\mathrm{X} 1$ scale is not obvious, but may be explained by the extended support to the parents that the medical staff are likely to give in such an occasion. Our study also detected an association at the $10 \%$ significant level between intraventricular hemorrhage (IVF) grade 1 or 2 and high levels of maternal traumarelated problems measured by IES (Table 4). IVF grade 1 or 2 is less severe than grade 3 or 4 which may be reflected in the level of support to the parents from the medical staff. The parents on the other hand could be distressed by the IVF grade 1 or 2 condition and be worried that the IVF incidence will have an negative influence on their baby's development.

\section{Strength/limitations}

The preterm participants came from well-defined geographic areas and were included consecutively in the 
study, thus minimizing selection bias. The response rate is high. The psychometric instruments (IES, GHQ, STAI) used in our study are all well-validated. We have assessed several important aspects of mental health problems, like psychological distress, anxiety, and traumarelated stress and also assessed tentative clinical diagnosis for the prevalence of mental health problems.

The present study describes a small group of mothers giving preterm birth with higher educational attainments, older age and higher socioeconomic status than would be found in a typical population of mothers who deliver preterm in Norway. Thus, one should be cautious about generalizing from this study. The homogeneity of the study group in terms of socio-demographic background and distress related to it is clearly a limitation in this study. On the other hand our results were controlled for highrisk socio-economic background variables. A more detailed assessment of maternal trauma related experiences prior to the pregnancy would of course have strengthened our study. However, data was collected of the study group's mental history and about their pregnancy experiences.

A tentative clinical diagnosis based on information from the standardized self reports was assessed by a psychiatrist. A diagnostic semistructured interview, however, would have been preferable in addition to information from psychometric self-report questionnaires to make a correct clinical diagnosis.

\section{Conclusions}

Our study revealed a substantial level of psychological distress in mothers who deliver preterm. Posttraumatic stress was the most common psychological reaction to preterm delivery in this study. Significant physical predictors that were discovered should be further investigated. Our findings imply that mothers' psychological reactions to preterm birth need to be taken into account at maternity wards. The need for intervention and psychotherapy should be considered at an early stage and while the infant still is in the NICU. It is, however, necessary to investigate these results closer in a prospective and longitudinal study as these psychological patterns might change over time.

\section{Competing interests}

The authors declare that they have no competing interests.

\section{Authors' contributions}

The first author ARM initiated the study, collected and organized the data. ARM and THD performed the statistical analyses. ARM, PN and THD designed and critically revised the study, approved the final version of the paper, and are accountable for all aspects of the work.

\section{Acknowledgements}

The authors would like to thank the participants, the neonatal intensive care unit at Rikshospitalet, Oslo University Hospital, and particularly the parents who participated in the study.

The study was supported by the Centre for Child and Adolescent Mental Health, Eastern and Southern Norway, the Department of Children's Division, Oslo University Hospital and the University College of Oslo and Akershus.

\section{Author details}

${ }^{1}$ Faculty of Health Sciences, University College of Oslo and Akershus, PO Box. 4 St. Olavs plass, N-0130 Oslo, Norway. ${ }^{2}$ Department of Clinical Neurosciences for Children, Women and Children's Division, Oslo University Hospital, Rikshospitalet, PO Box 4950 Nydalen, NO-0424 Oslo, Norway. ${ }^{3}$ Department of Medicine, Institute of Clinical Medicine, University of Oslo, PO Box 1171 Blindern, 0318 Oslo, Norway.

Received: 3 July 2014 Accepted: 5 August 2014

Published: 9 August 2014

\section{References}

1. Zaers S, Waschke M, Ehlert U: Depressive symptoms and symptoms of post-traumatic stress disorder in women after childbirth. J Psychosom Obstet Gynaecol 2008, 29(1):61-71.

2. Calam R, Lambrenos K, Cox A, Weindling A: Maternal appraisal of information given around the time of preterm delivery. J Reprod Infant Psychol 1999, 17(3):267-280.

3. Hammen C, Brennan PA, Shih JH: Family discord and stress predictors of depression and other disorders in adolescent children of depressed and nondepressed women. J Am Acad Child Adolesc Psychiatry 2004, 43(8):994-1002.

4. Goodman S, Rouse M, Connell A, Broth M, Hall C, Heyward D: Maternal depression and child psychopathology: a meta-analytic review. Clin Child Fam Psychol Rev 2011, 14(1):1-27.

5. Spear ML, Leef $K$, Epps S, Locke R: Family reactions during infants' hospitalization in the neonatal intensive care unit. Am J Perinatol 2002, 19(04):205,214.

6. Hughes M, McCollum J, Sheftel D, Sanchez G: How parents cope with the experience of neonatal intensive care. Child Health Care 1994, 23(1):1-14.

7. Seideman RY, Watson MA, Corff KE, Odle P, Haase J, Bowerman JL: Parent stress and coping in NICU and PICU. J Pediatr Nurs 1997, 12(3):169-177.

8. Kaaresen PI, Rønning JA, Ulvund SE, Dahl LB: A randomized, controlled trial of the effectiveness of an early-intervention program in reducing parenting stress after preterm birth. Pediatrics 2006, 118:9-19.

9. Singer LT, Salvator A, Guo S, Collin M, Lilien L, Baley J: Maternal psychological distress and parenting stress after the birth of a very low-birth-weight infant. JAMA 1999, 281(9):799-805

10. Vigod SN, Villegas L, Dennis CL, Ross LE: Prevalence and risk factors for postpartum depression among women with preterm and low-birth-weight infants: a systematic review. BJOG 2010, 117(5):540-550.

11. Achenbach TM: A nine-year outcome of the Vermont Intervention Program for low birth weight infants. Pediatrics 1993, 91(1):45-55.

12. Kersting A, Dorsch M, Wesselmann U, Ludorff K, Witthaut J, Ohrmann P, Hornig-Franz I, Klockenbusch W, Harms E, Arolt V: Maternal posttraumatic stress response after the birth of a very low-birth-weight infant. J Psychosom Res 2004, 57(5):473-476.

13. Bhutta AT, Cleves MA, Casey PH, Cradock MM, Anand KS: Cognitive and behavioral outcomes of school-aged children who were born preterm: a meta-analysis. JAMA 2002, 288(6):728-737.

14. Beck $C T$ : The effects of postpartum depression on maternal-infant interaction: a meta-analysis. Nurs Res 1995, 44(5):298-304.

15. Rahman A, lqbal Z, Bunn J, Lovel H, Harrington $\mathrm{RH}$ : Impact of maternal depression on infant nutritional status and illness: a cohort study. Arch Gen Psychiatry 2004, 61(9):946-952.

16. Halligan SL, Murray L, Martins C, Cooper PJ: Maternal depression and psychiatric outcomes in adolescent offspring: a 13-year longitudinal study. J Affect Disord 2007, 97(1):145-154.

17. Lyons-Ruth K, Wolfe R, Lyubchik A, Steingard R: Depressive Symptoms in Parents of Children under Age 3: Sociodemographic Predictors, Current Correlates, and Associated Parenting Behaviors. In Child Rearing in America: Challenges Facing Parents with Young Children. edn. Edited by Halfon N, McLearn KT, Schuster MA. NewYork: Cambrigde University Press; 2002:217-259

18. Poobalan A, Aucott L, Ross L, Smith W, Helms P, Williams J: Effects of treating postnatal depression on mother-infant interaction and child development: systematic review. Br J Psychiatry 2007, 191(5):378-386.

19. Mv P, Wolf H, Schultz WW, Neeleman J, Aarnoudse J: Posttraumatic stress disorder following preeclampsia and HELLP syndrome. J Psychosom Obstet Gynaecol 2004, 25(3-4):183-187. 
20. Jotzo M, Poets CF: Helping parents cope with the trauma of premature birth: an evaluation of a trauma-preventive psychological intervention. Pediatrics 2005, 115(4):913-919.

21. Muller-Nix C, Forcada-Guex M, Pierrehumbert B, Jaunin L, Borghini A Ansermet F: Prematurity, maternal stress and mother-child interactions. Early Hum Dev 2004, 79(2):145-158.

22. Pierrehumbert B, Nicole A, Muller-Nix C, Forcada-Guex M, Ansermet F: Parental post-traumatic reactions after premature birth: implications for sleeping and eating problems in the infant. Arch Dis Child 2003, 88(5):400-404

23. Solhaug M, Bjõrk I, Sandtrõ H: Staff perception one year after implementation of the the newborn individualized developmental care and assessment program (NIDCAP). J Pediatr Nurs 2010, 25(2):89-97.

24. Horowitz MJ, Wilner N, Alvarez W: Impact of event scale: a measure of subjective stress. Psychosom Med 1979, 41(3):209-218.

25. Sundin EC, Horowitz MJ: Horowitz's impact of event scale evaluation of 20 years of use. Psychosom Med 2003, 65(5):870-876.

26. Goldberg D, Williams P: A User's Guide to the General Health Questionnaire. London: Nfer-Nelson; 1991

27. Malt $\mathrm{U}$ : The validity of the general health questionnaire in a sample of accidentally injured adults. Acta Psychiatr Scand 1989, 80:103-112.

28. Goodwin L, Ben-Zion I, Fear NT, Hotopf M, Stansfeld SA, Wessely S: Are reports of psychological stress higher in occupational studies? A systematic review across occupational and population based studies. PLOS ONE 2013, 8(11):e78693.

29. Spielberger CD, Goursch RL, Luschene RE: STAI Manual for the State-Trait Anxiety Inventory. California: Palo Alto: Consulting Psychologists Press; 1970

30. Organization WH: The ICD-10 Classification of Mental and Behavioural Disorders: Clinical Descriptions and Diagnostic Guidelines. Geneva: World Health Organization; 1992.

31. Kringlen E: Trekk fra internasjonal psykiatrisk epidemiologi. Norwegian J Epidemiol 2002, 12(3):173-179.

32. Kringlen E, Torgersen S, Cramer V: A Norwegian psychiatric epidemiological study. Am J Psychiatr 2001, 158(7):1091-1098.

33. Dalgard OS: Psykiatrisk epidemiologi i Norge-et historisk tilbakeblikk. Norwegian J Epidemiol 2002, 12(3):163-172.

34. Kringlen E: Psykiatri, vol. 9 utg. Oslo: Gyldendal akademisk; 2008.

35. Skari H, Skreden M, Malt UF, Dalholt M, Ostensen AB, Egeland T, Emblem R: Comparative levels of psychological distress, stress symptoms, depression and anxiety after childbirth - a prospective population-based study of mothers and fathers. BJOG 2002, 109(10):1154-1163.

36. Holditch-Davis D, Miles MS, Weaver MA, Black B, Beeber L, Thoyre S, Engelke

S: Patterns of distress in African American mothers of preterm infants. J Dev Behav Pediatr 2009, 30(3):193.

37. Skari H, Malt UF, Bjornland K, Egeland T, Haugen G, Skreden M, Dalholt Björk M, Bjornstad Ostensen A, Emblem R: Prenatal diagnosis of congenital malformations and parental psychological distress-a prospective longitudinal cohort study. Prenat Diagn 2006, 26(11):1001-1009.

38. Kaasen A, Helbig A, Malt U, Næs T, Skari H, Haugen G: Acute maternal social dysfunction, health perception and psychological distress after ultrasonographic detection of a fetal structural anomaly. BJOG 2010, 117(9):1127-1138.

39. Alhusen JL: A literature update on maternal-fetal attachment. J Obstet Gynecol Neonatal Nurs 2008, 37(3):315-328.

40. Salisbury A, Law K, LaGasse L, Lester B: Maternal-fetal attachment. JAMA 2003, 289(13):1701

41. Pederson DR, Bento S, Chance GW, Evans B, Fox AM: Maternal emotional responses to preterm birth. Am J Orthopsychiatry 1987, 57(1):15-21.

42. Brisch $\mathrm{KH}$, Bechinger D, Betzler $\mathrm{S}$, Heinemann $\mathrm{H}$ : Early preventive attachment-oriented psychotherapeutic intervention program with parents of a very low birthweight premature infant: results of attachment and neurological development. Attach Hum Dev 2003, 5(2):120-135.

43. Korenromp M, Page-Christiaens G, van den Bout J, Mulder E, Hunfeld J, Potters C, Erwich J, van Binsbergen C, Brons J, Beekhuis J, Omtzigt AWJ, Visser OHA: A prospective study on parental coping 4 months after termination of pregnancy for fetal anomalies. Prenat Diagn 2007 27(8):709-716.

44. Brisch $\mathrm{KH}$, Kerr C: Maternal fear of loss and infant anxiety of physical pain Special triggers in mothers and former preterm infant. In 5th International Attachment Conference-IAC: 19-21 August 2011; Oslo, Norway.

45. Bowlby J: Attachment and Loss: Volume 1: Attachment, vol. 79; 1969.
46. Czarnocka J, Slade P: Prevalence and predictors of post-traumatic stress symptoms following childbirth. Br J Clin Psychol 2000, 39(1):35-51.

47. DeMier RL, Hynan MT, Hatfield RF, Varner MW, Harris HB, Manniello RL: A measurement model of perinatal stressors: identifying risk for postnatal emotional distress in mothers of high-risk infants. J Clin Psychol 2000, 56(1):89-100.

48. Rep A, Ganzevoort W, Bonsel GJ, Wolf H, de Vries Jl: Psychosocial impact of early-onset hypertensive disorders and related complications in pregnancy. Am J Obstet Gynecol 2007, 197(2):158. e1-6

49. Gennaro S, Brooten D, Roncoli M, Kumar SP: Stress and health outcomes among mothers of low-birth-weight infants. West J Nurs Res 1993, 15(1):97-113.

50. Philipp C: The role of recollected anxiety in parental adaptation to low birthweight infants. Child Psychiatry Hum Dev 1983, 13(4):239-248.

51. Redshaw M: Mothers of babies requiring special care: attitudes and experiences. J Reprod Infant Psychol 1997, 15(2):109-120.

52. Blom EA, Jansen PW, Verhulst FC, Hofman A, Raat H, Jaddoe WW, Coolman M, Steegers EAP, Tiemeier $\mathrm{H}$ : Perinatal complications increase the risk of postpartum depression. The Generation R Study. BJOG 2010, 117(11):1390-1398.

doi:10.1186/1471-2393-14-263

Cite this article as: Misund et al:: Mental health in women experiencing preterm birth. BMC Pregnancy and Childbirth 2014 14:263.

\section{Submit your next manuscript to BioMed Central and take full advantage of:}

- Convenient online submission

- Thorough peer review

- No space constraints or color figure charges

- Immediate publication on acceptance

- Inclusion in PubMed, CAS, Scopus and Google Scholar

- Research which is freely available for redistribution 